\title{
SIZE MATTERS FOR LIQUIDITY: EVIDENCE FROM EMU SOVEREIGN YIELD SPREADS.
}

\author{
Marta Gómez-Puig* \\ Universitat de Barcelona and Barcelona Stock Exchange. \\ First Version: November 2004. \\ Revised Version: April 2005.
}

Abstract

The objective is to study the relative importance of domestic components of EMU sovereign yield spreads since the start of Monetary Integration. The results indicate a change in the market value of liquidity, as measured by market size, after EMU.

JEL Classification Numbers: E44, F36, G15.

Keywords: Monetary integration, sovereign securities' markets, international and domestic credit risk, and market liquidity.

\footnotetext{
* Departament de Teoria Econòmica. Universitat de Barcelona. Diagonal 690, Barcelona 08034. Spain. T: 34-934.021.937. Fax: 34-934.021.937.E-mail: marta.gomezpuig@ub.edu. ). I would like to thank the Economics Department at the MIT for their hospitality and the Spanish Ministry of Education for their financial support. I am grateful to Rudi Dornbusch, Roberto Rigobon and all the participants at the International Breakfast Workshop at MIT for their useful comments on a very preliminary draft of the paper. Special thanks to Lorenzo Codogno, Jordi Galí, Alessandro Missale, Juergen von Hagen and Jaume Ventura, for their insightful comments on previous versions. I alone am responsible for any errors remaining in the final version..
} 


\section{Introduction.}

The removal of the foreign exchange risk in January 1999 and the elimination (or reduction to insignificant levels) of different tax treatments during the 90s eliminated two of the main components of EMU sovereign yield differentials, which prompted a significant convergence in spreads over 10 year German securities during the period January 1999December 2001. Nevertheless, the convergence only brought about a sizeable reduction in relative borrowing costs in the countries that presented wider spreads, lower rating and higher foreign exchange risk. Conversely, the countries that benefited less from the elimination of the exchange rate risk experienced an increase in their relative borrowing costs (see table 1). The objective of this paper is twofold: first, to decompose European yield spreads into the two main domestic risk components (liquidity and credit risk differences) that remain after the EMU; second, to determine whether there has been a change in the price assigned to them by markets, since the introduction of the euro. However, this analysis first requires a correction of pre-EMU spreads for the foreign exchange factor. Thus, following Favero et al.(1997) we break down the total differential over German securities into two components: (i) the foreign exchange factor and (ii) other factors, where the first component is estimated as the differential between the 10-year swap rate in the currency of denomination of the corresponding bond and the 10-year swap rate in Deutschemarks. Interestingly, once adjusted for the swap differential, spreads rose for all countries after Currency Union (see table 1). The sample is composed of daily data from January 1996 to December 2001 (the same extension is then considered both for the preEMU and the EMU period) and includes all EMU countries except Luxembourg and Greece. We use the credit rating as a proxy to measure differences in credit risk, and both the bid/ask spread and the overall outstanding amount of public debt securities for each issuer, in the case of differences in market liquidity (the independent variables are all relative to the German values). The main results of the analysis show a change in the market assessment of relative market size values. Specifically, they suggest the existence of a non-linear relationship between relative indebtedness levels and adjusted spreads, which was accentuated by EMU. The rest of the paper is organized as follows: Section 2 presents some considerations on credit risk and market liquidity; section 3 describes the data, section 4 explains the estimation method and reports the results; finally, section 5 draws conclusions.

\section{Credit risk and market liquidity.}

Firstly, we will assess whether EMU increased credit risk by denying governments the emergency exit of money creation and by stating that neither the ECB nor individual governments can be obliged to bail out troubled governments or whether, on the other hand, the maximum threshold that countries have had since EMU for both their budget deficit and level of public indebtedness actually resulted in a decrease in perceived credit risk. To do so, we will use credit rating will be used as a proxy to measure differences in credit risk. Even though there is the risk that ratings may be ex-post measures of fiscal sustainability, we think that they present an advantage over other measures, such as the debt-to-GDP ratio in that they potentially affects the creditworthiness of the governments but not the liquidity of their public debt issues $^{1}$. Ratings then seem to be the best variable for use in the model where the relative level of indebtedness is used as a proxy of market depth; otherwise, multicollinearity would pose a significant problem. Secondly, the introduction of the euro reduced some segmentation among euro-area government bond markets as exchange risk removal brought down a major barrier that previously had fostered captive domestic markets. In this more competitive scenario, the

\footnotetext{
${ }^{1}$ However, when we have estimated the same model using the debt-to-GDP ratio as a proxy of credit risk and only the bid/ask spread as a proxy of market liquidity very similar results were obtained.
} 
second point that we will study is whether market liquidity differences increased their relevance. We use two proxy variables to measure this effect: the bid/ask spread and the overall outstanding volume of sovereign debt. The former reflects the cost incurred by a typical investor in unwinding an asset position and measures market tightness. The latter is considered a measure of market depth because larger markets may present lower information costs since their securities are likely to trade frequently and a relative large number of investors may own or have analysed their features. Inoue (1999) states that in G10 countries, the larger the outstanding stock of publicly issued central government debt, generally the higher the turnover in cash and futures trading, and the better the liquidity. Martin and Rey (2004) show that, in general, size matters for asset trade, that is a larger country will benefit more from higher asset prices than a smaller one. McCauley and Remolona (2000) note that if important fixed costs are involved in producing information on the future path of interest rates, the size of the whole debt market matters. In particular, they estimate that there may be a size threshold of around $\$ 100-200$ billions, below which sustaining a liquid government market may not be easy (table 2 shows that only five countries in the euro-area are above this threshold). Finally, Economides and Siow (1988) point out that there might be a trade-off between liquidity and market size. Hence, if size matters for liquidity, "ex-ante" traders will prefer bigger and liquid markets, so liquidity will be "self-reinforcing". To the best of our knowledge no empirical analyses have been published to date using a daily dataset for one of the most important measures of liquidity, the bid/ask spreads, which corresponds to the trading activity that takes place in the whole of the euro-securities market.

\section{Data description.}

As we need to correct pre-EMU yield spreads for the foreign exchange component, we thus approximate the expected exchange rate change to the swap differential. So, we denominate:

$I_{i, 10}=10$-year Yield on sovereign bonds of country $i$

$\operatorname{IR} S_{i, 10}=10$-years Interest Rate Swap rate of currency $i$

Where, considering that differences in tax-regimes have been reduced to insignificant levels during the 1990s:

$I_{i, 10}=f\left(D R_{i, 10}, L_{i, 10}, E R_{i, 10}\right)$

$D R_{i, 10}=$ Default risk of country $i 10$-year sovereign bonds.

$L_{i, 10}=$ Liquidity of country $i 10$-year sovereign bonds.

$E R_{i, 10}=$ Exchange rate risk of currency $i$ over a 10 -year horizon.

Therefore the 10-year yield differential of country $i$ over Germany will be:

$\left[I_{i, 10}-I_{G E, 10}\right]_{t}=f\left(\left[D R_{i, 10}-D R_{G E, 10}\right]_{t},\left[L_{i, 10}-L_{G E, 10}\right]_{t},\left[E R_{i, 10}-E R_{G E, 10}\right]_{t}\right)$

Then aproximating:

$$
\left[I R S_{i, 10}-I R S_{G E, 10}\right]_{t}=\left[E R_{i, 10}-E R_{G E, 10}\right]_{t}
$$

The variable "ADJUSTED SPREAD," i.e. the difference between the total yield differential and the swap rate differential, which will be used as the dependant variable, will mainly account for credit risk and market liquidity differences of country is sovereign securities over Germany.

YIELD SPRE $A D_{i t}=\left[I_{i, 10}-I_{G E, 10}\right]_{t}=f\left(\left[D R_{i, 10}-D R_{G E, 10}\right]_{t},\left[L_{i, 10}-L_{G E, 10}\right]_{t},\left[E R_{i, 10}-E R_{G E, 10}\right]_{t}\right)$ 
ADJUSTED SPRE $A D_{i t} \quad=A S P R E A D_{i t}=$

$$
=\left[I_{i, 10}-I_{G E, 10}\right]_{t}-\left[\operatorname{IR} S_{i, 10}-I R S_{G E, 10}\right]_{t}=f\left(\left[D R_{i, 10}-D R_{G E, 10}\right]_{t},\left[L_{i, 10}-L_{G E, 10}\right]_{t}\right)
$$

Yields and swap rates are obtained from Datastream and correspond to the "on the run" (benchmark) 10-year issue for each market at every moment of time. They are quoted rates at market close. Datastream creates continuous yield series by taking the yield from the current benchmark in each market and using this to update a separate time series. As a benchmark changes, data are taken from a new stock on the first day of the month. With regard to the explanatory variables, for the credit rating, a scale (see Blanco 2001) is calculated using both Standard \& Poor's and Moody's ratings which have been obtained from Bloomberg. In the case of the bid/ask spreads series, daily time-series are created by calculating the spread between the bid and ask quotations provided by Bloomberg for the "on the run" (benchmark) 10year issue for each market at every moment of time, using the benchmarks and starting dates that Datastream uses to create the 10-year yields and swap rates series. For all the different issues, Bloomberg provides daily quoted prices calculated as the average bid and ask quotations at the close. Finally, the overall outstanding amounts of public debt data are taken from the Bank for International Settlements (BIS; see table 2). However, as these series are only provided eacj quarter, we build up the relative level of indebtedness daily time-series, extrapolating the rest of the data by assuming a daily constant rate of increase of those volumes, which in fact present very slight differences within countries throughout the studied period. For this reason, it can be assumed that the extrapolation will not produce significant biases in the data and can be applied in this case. All the variables included in the estimation are relative to the German ones, as our dependant variable $\left(A S P R E A D_{i t}\right)$ is the difference between the total yield differential and the swap differential of country $i$ over Germany. Therefore, BIDASKDIF it is the difference between the bid/ask spread in country $i$ and the bid/ask spread in Germany, OUTDEBTRAT $T_{i t}$ is the ratio of the overall outstanding amount of sovereign debt in country $i$ to the overall amount in Germany, and RATINGDIF it is the difference between the rating scale value of country $i$ and that of Germany.

\section{Estimation and results.}

We carry out a panel estimation using Feasible Generalized Least Squares (FGLS), which are robust to the possible existence of autocorrelation and heteroscedasticity in the error terms. Besides, country and monthly dummy variables are introduced in the specification, in order to capture the potential existence of both specific features by countries and temporal effects. Moreover, as the goal is to analyse whether the marginal effect of the variables varies with the start of EMU, we also introduce a dummy (DPRE) that takes the value 1 in the pre-EMU period (and 0, otherwise), and calculate the coefficients of the interactions between this dummy and the rest of the variables. Finally, to assess whether there exists a varying relationship between relative debt levels and yield $A S P R E A D S_{i t}$ a quadratic specification for the variable OUTDEBTR $A T_{i t}$ is formulated. Therefore the estimated model is:

$y_{i t}=\alpha_{i}+\beta X_{i t}+\gamma$ DPRE $_{i t}+\delta M O N T H L Y D U M M I E S_{t}+\lambda$ COUNTRYDUMMIE $_{i}+\varepsilon_{i t}$

where previously defined: OUTDEBTR $A T 2_{i t}=\left(\operatorname{OUTDEBTR} A T_{i t}\right)^{2}$, the independent variables vector is:

$X_{i t}=\left(B I D A S K D I F_{i b}, O U T D E B T R A T_{i t}\right.$, OUTDEBTR AT2 $_{i b}$, ATINGDIF $\left._{i t}\right)$

In addition, $\beta=\beta_{1}+\beta_{2} D P R E_{i t}$

Hence, the marginal effect of a variable is: $\beta=\beta_{1}$ (in the EMU period), and $\beta=\beta_{1}+\beta_{2}$ (in the pre-EMU) 
Tables 3 shows the values and standard errors of the estimated coefficients. For each exogenous variable, this table presents the corresponding marginal effects for the EMU period $\left(\beta_{1}\right)$ and the pre-EMU $\left(\beta_{1}+\beta_{2}\right)$. The main conclusions are that a change in the market assessment of liquidity measured by both the bid/ask spreads and relative market size levels, rather than credit risk, could be the factor behind the rise in adjusted spreads with EMU. So, even though the results support the idea that $A S P R E A D S_{i t}$ carry a credit risk premium to compensate investors for bearing default risk, this premium does not increase with Monetary Integration. Conversely, the bid/ask spread marginal impact is not only positively significant in both periods, but also rises in the EMU period. Note that as market dealers reduce their liquidity risk, bid/ask spreads should narrow with trading activity (and hence with EMU). In this context, the estimation only shows that their "positively" significant marginal impact on $A S P R E A D S_{i t}$ has risen with EMU. This only means that their "significance", i.e., the value that agents give to market liquidity has increased with EMU; it does not necessarily mean that their value has risen (which, indeed, would be inconsistent with the effects one would expect from economies of scale in larger markets). In the case of the relative level of indebtedness, the results support the existence of a negative non-linear relationship in both periods, whose marginal impact on adjusted spreads rises in absolute terms with Currency Union (the smaller the market, the larger the increase). Therefore, especially for small markets, market size scale economies seem to have risen with EMU. Actually, the countries with a larger debt market relative to Germany (Italy, France and Spain) are the ones with the lowest rises in their adjusted spread (see tables 1 and 2) due to a decline in their liquidity premium. Along the same lines, other authors such as Bernoth et al. (2004) also state that after the start of EMU German government bond yields are still below those of bonds issued by governments with much better debt positions due to the size of their bond market, which seems to support our conclusions.

\section{Conclusions.}

Euro-area countries' adjusted spreads over 10-yr German securities experienced an average increase of 11.98 basis points after EMU. This resulted in a lower decrease in borrowing costs than expected. Our results show that a change in the market assessment of relative market size levels could be reason for this behaviour. In particular, the results support the existence of a non-linear relationship between relative debt levels and adjusted spreads which was accentuated by EMU. Therefore, as the German sovereign debt market is the second-biggest market in the euro-area, with Currency Union all countries may have experienced a decrease in their relative liquidity that has been translated in higher adjusted spreads. Hence, in the current context of increased competition among euro-area government securities markets their success might be limited by the extent of their liquidity and market size. 


\section{References}

Bernoth, K, J.Von Hagen and L. Schuknecht, 2004. Sovereign risk premia in the European Government Bond Market. European Central Bank working paper n. 369, June.

Blanco, R., 2001. The euro-area Government Securities Market: Recent Developments and Implications for Market Functioning. Documento de trabajo del Banco de España n. 0120.

Economides, N. and A.Siow, 1988. "The Division of Markets is Limited by the Extent of Liquidity (Spatial Competition with Externalities)". American Economic Review, Vol.78, n¹ pp 1719-1734.

Favero, Carlo, F.Giavazzi and L.Spaventa, 1997."High Yields: The Spread on German Interest Rate”. The Economic Journal, Vol.107, Issue 443.

Inoue, H., 1999.'The Structure of Government Securities Markets in G10 Countries: Summary of Questionnaire Results". BIS Committee on the Global Financial System Publications n.11.

Martin, P and H.Rey, 2004. Financial super-markets: size matters for asset trade. Journal of International Economics 64, pp. 335-361.

McCauley R. and E.Remolona, 2000. “Size and Liquidity of Government Bond Markets”. BIS Quarterly Review, November. 
TABLE 1

\begin{tabular}{|c|c|c|c|c|c|c|c|c|}
\hline & \multicolumn{3}{|c|}{ PRE-EMU (1996-1998) } & \multicolumn{3}{|c|}{ EMU (1999-2001) } & \multicolumn{2}{|c|}{$\begin{array}{c}\text { Diffeerences } \\
\text { between EMU and pre-EMU }\end{array}$} \\
\hline & $\left(\mathrm{I}_{\mathrm{i}}-\mathrm{I}_{\mathrm{DM}}\right)$ & $\left(\right.$ IRS $\left._{\mathrm{i}}-\mathrm{IRS}_{\mathrm{DM}}\right)$ & ASPREAD $_{i}$ & $\left(I_{i}-I_{D M}\right)$ & $\left(\right.$ IRS $\left._{\mathrm{i}}-\mathrm{IRS}_{\mathrm{DM}}\right)$ & ASPREAD $_{i}$ & $\left(\mathbf{i}_{\mathrm{i}}-\mathbf{i}_{\mathrm{DM}}\right)$ & ASPREAD $_{i}$ \\
\hline & (1) & (2) & $(3)=(1)-(2)$ & (4) & (5) & $(6)=(4)-(5)$ & $(4)-(1)$ & (6)-(3) \\
\hline AT & 9.07 & -0.33 & 9.40 & 24.42 & -0.01 & 24.43 & 15.34 & 15.03 \\
\hline BE & 33.06 & 4.29 & 28.77 & 46.30 & -0.01 & 46.31 & 13.24 & 17.53 \\
\hline FI & 43.56 & 41.31 & 2.25 & 21.95 & -0.01 & 21.96 & -21.61 & 19.71 \\
\hline IT & 157.73 & 133.04 & 24.69 & 32.32 & 0.05 & 32.27 & -125.40 & 7.58 \\
\hline NL & -2.70 & -3.52 & 0.83 & 14.22 & -0.01 & 14.23 & 16.92 & 13.40 \\
\hline PT & 111.73 & 91.42 & 20.31 & 31.85 & 0.22 & 31.63 & -79.88 & 11.31 \\
\hline SP & 118.06 & 97.99 & 20.07 & 27.24 & 0.04 & 27.20 & -90.82 & 7.13 \\
\hline
\end{tabular}

NOTE: AT: Austria, BE: Belgium, FI: Finland, FR: France, IE: Ireland, IT: Italy, NL: The Netherlands, PT: Portugal, SP: Spain. Source: Datastream. $\left(\mathrm{I}_{\mathrm{i}} \mathrm{IDM}_{\mathrm{DM}}\right)=10$-year yield difference over Germany. $\left(\mathrm{IRS}_{\mathrm{i}}-\mathrm{IRS}_{\mathrm{DM}}\right)=10$-year interest rate swap difference over Germany. ASPREADi $=\left(\mathrm{I}_{\mathrm{i}} \mathrm{IDM}_{\mathrm{DM}}\right)-$ $\left(\right.$ IRS $\left._{\mathrm{i}}-\mathrm{IRS}_{\mathrm{DM}}\right)$

TABLE 2

\begin{tabular}{|c|c|c|c|c|c|c|c|c|c|}
\hline \multicolumn{10}{|c|}{$\begin{array}{c}\text { DOMESTIC DEBT SECURITIES } \\
\text { PUBLIC SECTOR AMOUNTS OUTSTANDING } \\
\text { (Billions of euros) }\end{array}$} \\
\hline & 1995-12 & 1996-12 & 1997-12 & 1998-12 & 1999-12 & $2000-12$ & 2001-12 & average & $\%$ over EMU \\
\hline Ireland & 19.93 & 23.20 & 23.12 & 21.93 & 24.73 & 24.07 & 19.95 & 23.15 & 0.69 \\
\hline Portugal & 35.19 & 36.47 & 32.84 & 34.04 & 37.49 & 42.35 & 45.61 & 37.67 & 1.13 \\
\hline Finland & 33.20 & 38.15 & 41.56 & 44.28 & 45.60 & 47.70 & 46.28 & 43.39 & 1.30 \\
\hline Austria & 57.04 & 58.95 & 63.87 & 69.28 & 86.05 & 99.74 & 100.52 & 76.80 & 2.30 \\
\hline Greece & 64.10 & 79.58 & 84.47 & 84.80 & 88.43 & 96.73 & 102.20 & 87.23 & 2.62 \\
\hline Netherlands & 155.64 & 159.89 & 159.68 & 170.12 & 178.14 & 180.98 & 177.50 & 171.44 & 5.14 \\
\hline Belgium & 228.86 & 230.59 & 228.41 & 229.67 & 231.85 & 246.18 & 248.66 & 236.75 & 7.10 \\
\hline Spain & 211.07 & 241.63 & 259.63 & 272.41 & 287.34 & 311.04 & 299.43 & 269.56 & 8.09 \\
\hline France & 497.35 & 536.05 & 565.50 & 623.91 & 639.85 & 708.45 & 709.23 & 614.79 & 18.45 \\
\hline Germany & 676.53 & 682.74 & 699.45 & 738.75 & 767.35 & 816.77 & 790.81 & 734.97 & 22.05 \\
\hline Italy & 896.49 & 1022.19 & 1011.08 & 1037.09 & 1042.62 & 1088.36 & 1056.96 & 1036.69 & 31.11 \\
\hline EMU & 2875.40 & 3109.45 & 3169.63 & 3326.27 & 3429.43 & 3662.37 & 3597.15 & 3332.43 & 100.00 \\
\hline
\end{tabular}

Source: Bank for International Settlements

TABLE 3

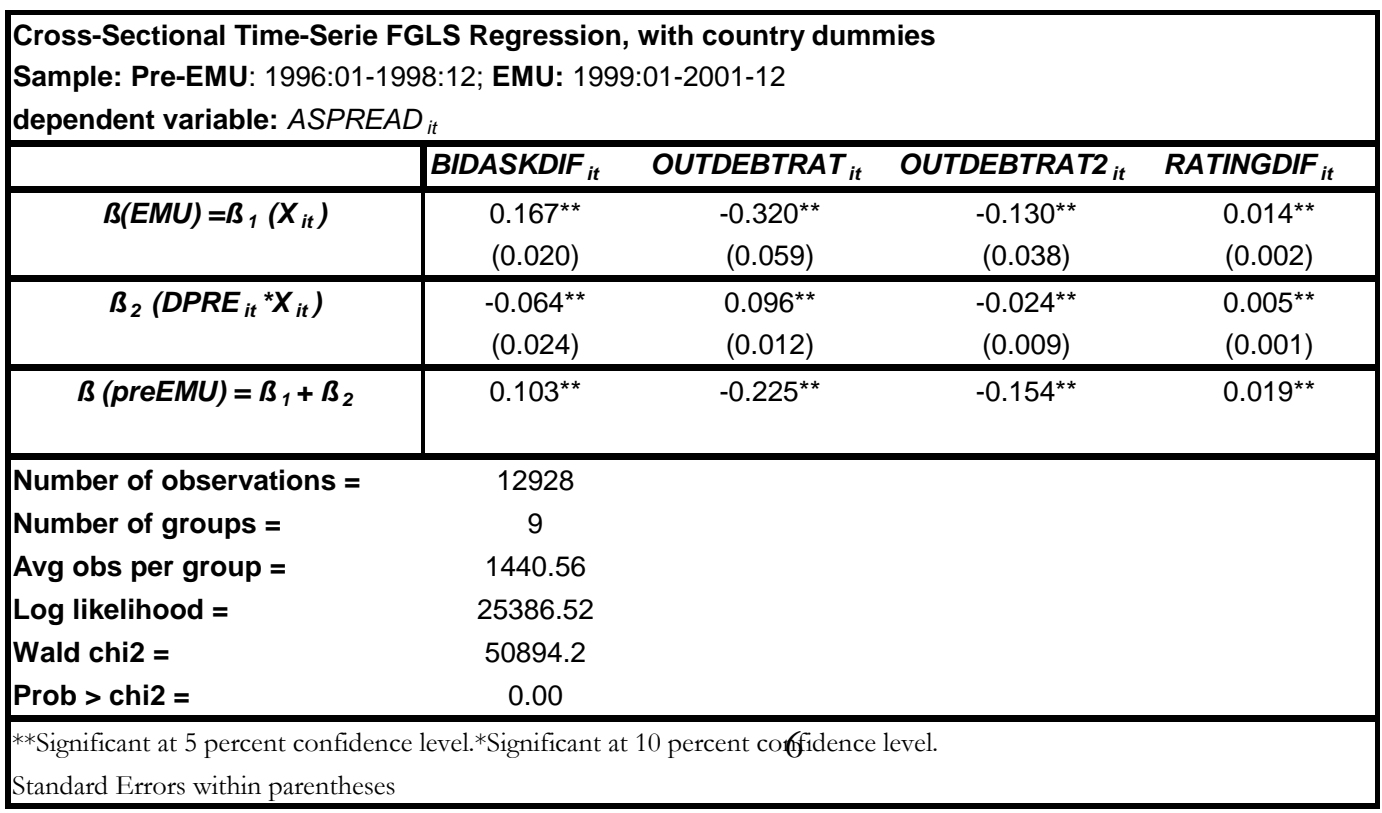

